\title{
The tip of antibody-testing iceberg
}

Neurol Neuroimmunol Neuroinflamm May 2020 vol. 7 no. 3 e716. doi:10.1212/NXI.0000000000000716

During the past decade, the field of Neuroimmunology has expanded at a rapid pace. For some disorders, particularly those related to paraneoplastic and neuronal cell-surface antibodies, this growth has been accompanied by an increase in, and reliance on, the use of antibody testing. This testing does not come free of problems, and when it leads to the wrong direction, it slows our progress forward with important diagnostic and treatment implications. In this issue of N2, several articles revolve around this topic.

To determine the accuracy of commercial immunoblots to detect the onconeuronal or classic paraneoplastic antibodies, Déchelotte et al. ${ }^{1}$ examined the sera of 5,300 patients with suspected paraneoplastic neurologic syndromes (PNS) with 1 or 2 different commercial tests. Those found positive were further studied with confirmatory tests including rat brain immunohistochemistry (IHC) and a recombinant protein-based test, either in-house immunoblot or cell-based assay (CBA). When one of the commercial tests was applied to 1,658 of the indicated sera, $128(8 \%)$ were found positive, and of these, only $47 / 128$ (37\%) were confirmed as truly positive for paraneoplastic antibodies. When the other commercial test was applied to 3,626 of the indicated sera, $186(5.1 \%)$ were positive, and of these, only 56/186 (30\%) were confirmed as positive. The authors indicate that the degree of correspondence between the commercial tests and the confirmatory techniques varied broadly according the antigens; for anti-Yo (or PCA1), one of the classic paraneoplastic antibodies, only $7 \%$ and $6 \%$ of those found positive by the commercial tests were eventually confirmed as positive. On the other hand, anti-Hu (or ANNA1) was confirmed in $88 \%$ and $65 \%$ of those found positive by the commercial tests. The study did not examine with confirmatory tests the serum samples that were found negative with commercial tests; therefore, sensitivity and specificity could not be established. Most of the false positive cases by commercial tests did not have the expected paraneoplastic neurologic syndrome (in many cases alternative diagnoses were established) and most did not have cancer. The authors conclude that although immunoblots may be useful for PNS screening, a threshold should be established for each antibody, and clinical information and confirmation by other techniques are essential. These findings should raise concern; first, the percentage of false positives is unacceptably high; second, the cost of the tests is considerable; and third, in clinical practice, the results of the tests frequently override the clinical assessment, leading to screenings to rule out inexistent tumors. In addition, false-positive results generate unnecessary anxiety to patients and families related to the concern for an occult cancer, which usually does not abate even when the screening is negative. Although the study of Déchelotte et al. did not include the antibodies against neuronal cell-surface proteins, the frequency of false-positive (and negative) results for some of these (e.g., NMDAR, LGI1, among others) is also unacceptably high. Most readers would likely agree that the findings for the onconeuronal antibodies in the study of Déchelotte indicate a failure of commercial tests in diagnosing PNS. By contrast, for the antibodies against neuronal cell-surface proteins, similar testing problems that are suggested by the extraordinary number of questionable positive cases being reported by clinical laboratories and in publications 
seems to have led to the opposite effect: instead of raising appropriate concern about the specificity of the tests, they have incorrectly been accepted as proof of high sensitivity (without indicating for what). This has promoted studies in which the antibodies are not properly characterized or confirmed with additional techniques, and these positive cases frequently identified among healthy participants or patients without the expected syndrome are accepted as proof of high test sensitivity. All considered the study of Déchelotte et al. likely reveals only the tip of the antibody-testing iceberg and strongly supports the need of similar investigations for diseases associated with antibodies against glial or neuronal cell-surface proteins and the development of antibody testing standards.

Different from the above-noted problems with onconeuronal and neuronal cell-surface antibodies, the challenges for glutamic acid decarboxylase (GAD) 65 antibodies are the interpretation of antibody concentrations, and when to establish a link with the neurologic symptoms, considering that these antibodies can also be found in patients with type I diabetes mellitus and patients without neurologic symptoms. To address these problems, Muñoz-Lopetegi et al. ${ }^{2}$ examined the serum and CSF (when available) of 56 patients with neurologic symptoms, using ELISA (for quantitative assessment) and rat brain IHC and CBA as confirmatory qualitative tests. An ELISA cutoff of $100 \mathrm{IU} / \mathrm{mL}$ showed $100 \%$ concordance among tests in the CSF. For the serum, using a cutoff value of 10,000 IU/ $\mathrm{mL}$, all low concentration samples had a negative IHC and 97\% of high concentration samples had a positive IHC. Most IHC results corresponded with the CBA results. Among the 36 patients identified in the high concentration group (as per the above indicated thresholds), 34 had typical anti-GADassociated neurologic syndromes, such as stiff-person syndrome (SPS), cerebellar ataxia, epilepsy, limbic encephalitis, or overlapping syndromes. On the other hand, 12 of the 20 patients in the low-concentration group had alternative diagnoses, and the other 8 had chronic epilepsy, otherwise seronegative limbic encephalitis or nonspecific ataxia and gait disorder. Treatment with immunotherapy led to the antibody concentration reduction, which in most patients associated with clinical improvement. The study represents an important step in interpreting the GAD-antibody results obtained by several different tests (radioimmunoassay was not included). Although the link between the indicated syndromes and high antibody titers seems to be clear, further studies are needed to clarify the clinical relevance of low GAD-antibody titers in patients with neurologic syndromes of unclear cause.

In another study, Esch and Newsome ${ }^{3}$ reported 2 patients who showed improvement of SPS during pregnancy and reviewed 5 previously published patients with SPS during pregnancy. Six of the 7 patients had GAD65 antibodies. Overall, 9 pregnancies (7 patients) were considered, showing that in $5(56 \%)$ of the pregnancies there was stabilization or improvement of SPS symptoms, leading to the reduction of symptomatic medications (antispasmodics). The authors indicate that most of these pregnancies in women with SPS were carried safely to term, with few or no complications for the mother or child, although 2 infants were found to harbor GAD65 antibodies. In the current issue of N2, another article by Joubert et al. ${ }^{4}$ examined the pregnancy outcomes in 32 patients with antiNMDAR encephalitis (11 new cases and 21 previously reported). These authors found that although pregnant patients with anti-NMDAR encephalitis often had obstetrical complications, most of the newborns were healthy and seemed to have normal development.

In another study, Altmann et al. ${ }^{5}$ described an 11-year-old girl who presented with a fulminant encephalopathy with lifethreatening cerebral edema requiring decompressive craniectomy. Biopsy during this procedure showed no evidence of a demyelinating process, despite the initial MRI findings suggesting acute disseminated encephalomyelitis. The patient was eventually diagnosed with complement factor I deficiency. The authors discuss the physiopathology of this interesting disorder, along with the clues that may suggest the diagnosis, treatments that may have deleterious effects (e.g., plasma exchange with fresh frozen plasma because of the delivery of exogenous, functional factor I and complement 3 ), and potentially useful treatments (e.g., eculizumab, a complement inhibitor).

Moving to a completely different topic, Hedström et al. ${ }^{6}$ investigated the association between fish consumption and MS. There are reports previously suggesting an inverse association between fish consumption and MS, which is also the case for vitamin $\mathrm{D}$ and sun exposure. However, given that both sun exposure and fish consumption are sources of vitamin $\mathrm{D}$, the extent of their individual contribution in reducing the risk of MS has been unclear. In the current study, based on the 2 large population-based case control studies (6,914 cases and 6,590 controls), the authors show that irrespective of the sun exposure habits, low fish consumption, including both lean and fatty fish, was associated with the increased risk of MS. Moreover, a mediation analysis did not support vitamin $\mathrm{D}$ as a mediator of the association between fish consumption and risk of MS. As suggested by the authors, the findings may be relevant for prevention, in particular, for patients with a genetic susceptibility to MS.

In another study Bringeland et al. ${ }^{7}$ investigated whether the wearing-off symptoms at the end of the natalizumab dosing interval were associated with clinical and demographic patient characteristics or with natalizumab-receptor occupancy on leucocytes. In a cross-sectional assessment of 40 patients with relapsing-remitting MS receiving natalizumab, the authors found that patients who usually had wearing-off symptoms had lower natalizumab receptor occupancy compared with patients who never or only sometimes had these symptoms. The group with frequent wearing-off symptoms also had higher body mass index suggesting that it associated with lower receptor occupancy. As indicated by the authors, further studies are 
needed to determine whether increasing receptor occupancy by reducing patients' weight or dosing intervals may mitigate the wearing-off symptoms.

In addition to these studies, the May issue of $\mathrm{N} 2$ contains other interesting articles that I hope will catch your attention.

\section{Study funding}

No targeted funding.

\section{Disclosure}

Dr. Dalmau holds patents for the use of Ma2, NMDAR, GABABR, GABAAR, DPPX, and IgLON5 as autoantibody tests and receives royalties from the use of these tests. He is Editor of Neurology ${ }^{\oplus}$ : Neuroimmunology \& Neuroinflammation. Go to Neurology.org/NN for full disclosures.

\section{References}

1. Déchelotte B, Muniz-Castrillo, Joubert B, et al. Diagnostic yield of commercial immunodots to diagnose paraneoplastic neurologic syndromes. Neurol Neuroimmunol Neuroinflamm 2020;7:e701. doi: 10.1212/NXI.0000000000000701.

2. Muñoz-Lopetegi A, de Bruijn M, Boukhrissi S, et al. Neurologic syndromes related to anti-GAD65: Clinical and serologic response to treatment. Neurol Neuroimmunol Neuroinflamm 2020;7:e696. doi:10.1212/NXI.0000000000000696.

3. Esch ME, Newsome SD. Improvement of stiff-person syndrome symptoms in pregnancy: Case series and literature review. Neurol Neuroimmunol Neuroinflamm 2020; 7:e684. doi:10.1212/NXI.0000000000000684.

4. Joubert B, Garcia-Serra, Planaguma J, et al. Pregnancy outcomes in anti-NMDAR encephalitis: Case series. Neurol Neuroimmunol Neuroinflamm 2020;7:e668. doi:10.1212/ NXI.0000000000000668.

5. Altmann T, Torell M, Owens S, et al. Complement factor I deficiency: A potentially treatable cause of fulminant cerebral inflammation. Neurol Neuroimmunol Neuroinflamm 2020;7:e689. doi:10.1212/NXI.0000000000000689.

6. Hedström AK, Olsson T, Kockum I, Hillert J, Alfredsson L. Low fish consumption is associated with a small increased risk of MS. Neurol Neuroimmunol Neuroinflamm 2020;7: e717. doi: 10.1212/NXI.0000000000000717.

7. Bringeland GH, Blaser N, Kjell-Morten M, Vedeler CA, Gavasso S. Wearing-off at the end of natalizumab dosing intervals is associated with low receptor occupancy. Neurol Neuroimmunol Neuroinflamm 2020;7:e678. doi:10.1212/NXI.0000000000000678. 


\section{Neurology \\ Neuroimmunology \& Neuroinflammation}

The tip of antibody-testing iceberg

Neurol Neuroimmunol Neuroinflamm 2020;7;

DOI 10.1212/NXI.0000000000000716

This information is current as of April 10, 2020

\section{Updated Information \& Services}

References

Permissions \& Licensing

\section{Reprints}

including high resolution figures, can be found at: http://nn.neurology.org/content/7/3/e716.full.html

This article cites 7 articles, 7 of which you can access for free at: http://nn.neurology.org/content/7/3/e716.full.html\#\#ref-list-1

Information about reproducing this article in parts (figures,tables) or in its entirety can be found online at:

http://nn.neurology.org/misc/about.xhtml\#permissions

Information about ordering reprints can be found online: http://nn.neurology.org/misc/addir.xhtml\#reprintsus

Neurol Neuroimmunol Neuroinflamm is an official journal of the American Academy of Neurology.

Published since April 2014, it is an open-access, online-only, continuous publication journal. Copyright

Copyright (C) 2020 The Author(s). Published by Wolters Kluwer Health, Inc. on behalf of the American Academy of Neurology.. All rights reserved. Online ISSN: 2332-7812.

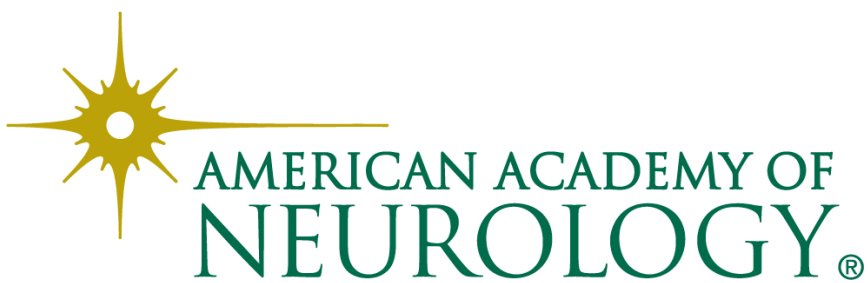

